\title{
BMJ Open Risk factors and regional variations of malnutrition among children under 5 in Myanmar: cross-sectional analyses at national and subnational levels
}

\author{
Hnin Thiri Khaing, ${ }^{1}$ Shuhei Nomura, ${ }^{1}$ Daisuke Yoneoka, ${ }^{\odot 1,2}$ Peter Ueda, ${ }^{1,3}$ \\ Kenji Shibuya ${ }^{1,4}$
}

To cite: Khaing HT, Nomura S, Yoneoka D, et al. Risk factors and regional variations of malnutrition among children under 5 in Myanmar: cross-sectional analyses at national and subnational levels. BMJ Open 2019;9:e030894. doi:10.1136/ bmjopen-2019-030894

- Prepublication history and additional material for this paper are available online. To view please visit the journal (http:// dx.doi.org/10.1136/bmjopen2019-030894).

Received 24 April 2019 Revised 08 August 2019 Accepted 12 August 2019

Check for updates

(C) Author(s) (or their employer(s)) 2019. Re-use permitted under CC BY-NC. No commercial re-use. See rights and permissions. Published by BMJ.

${ }^{1}$ Department of Global Health Policy, Graduate School of Medicine, The University of Tokyo, Tokyo, Japan ${ }^{2}$ Institution of Statistical Mathematics, Tokyo, Japan ${ }^{3}$ Division of Clinical Epidemiology, Department of Medicine, Solna, Karolinska Institute, Stockholm, Sweden

${ }^{4}$ Institute for Population Health, King's College London, London, UK

Correspondence to Dr Hnin Thiri Khaing; khaing.hninthiri@gmail.com

\section{ABSTRACT}

Objective The levels, distributions of child malnutrition and its potential risk factors are not very well known in Myanmar. The objectives included in this study were: to estimate the current national and subnational prevalence of four types of malnutrition (stunting, wasting, underweight and overweight) among children under 5 in Myanmar; to identify potential risk factors associated with each type of malnutrition and to investigate how the identified risk factors' distributions explained the regional disparities in malnutrition prevalence.

Design/methods Data from the Myanmar Demographic and Health Survey 2015-2016 were used to estimate the prevalence of four types of malnutrition at both national and subnational levels (15 regions). Logistic regression models were applied to examine the association between each type of malnutrition and its risk factors, including child's factors, parental social status and household conditions. The risk factor-adjusted prevalence of the malnutrition was estimated at the subnational level based on the estimated parameters from the regression models. Results The national prevalence of stunting, wasting, underweight and overweight in children under 5 was estimated to be $29.1 \%$ (95\% Cl $27.7 \%$ to $30.6 \%), 6.8 \%$ (6.0\% to $7.6 \%), 18.3 \%$ (17.0\% to $19.5 \%$ ) and $1.5 \%(1.1 \%$ to $1.9 \%$, respectively. Substantial regional variations in the prevalence of each type of malnutrition were observed. Several risk factors of each type of malnutrition were identified, including low birth weight (LBW) and inadequate maternal nutritional status. Except for overweight, regional variations largely persisted even after adjustment for the risk factors investigated.

Conclusion The prevalence of malnutrition among children under 5 is still high in Myanmar, most commonly stunting. Targeted interventions aimed at prevention of LBW, improving the maternal nutritional status, in addition to other sociodemographic conditions should be encouraged urgently. Further research is necessary to investigate the potential sources of regional variation in prevalence of malnutrition among children under 5 in the country.

\section{INTRODUCTION}

Malnutrition, defined by WHO as any deficiencies, excess or imbalances in a person's
Strengths and limitations of this study

- This is the first study to report the prevalence of malnutrition among children under 5 in Myanmar at the national and subnational level using nationally representative data.

- We identified several risk factors of malnutrition, which might be useful for designing interventions aiming to improve nutritional status among children in Myanmar.

- Measuring variation in malnutrition at subnational level and its potential contributing factors is critical to understand the existing disparities in malnutrition across the country and formulate tailored strategies and policies to effectively manage malnutrition.

- The cross-sectional and observational nature of the study did not allow to identify factors that are causally related to malnutrition.

intake of nutrients, ${ }^{1}$ constitutes many cases of morbidity and mortality in children under 5 , especially in developing countries. ${ }^{2}$ Almost $50 \%$ of total deaths among children under 5 are attributable to undernutrition. ${ }^{3}$ Malnutrition also impacts the economic growth of nations by causing loss in productivity. ${ }^{4}$

During the last three decades, the epidemiology of malnutrition has changed considerably worldwide: undernutrition has decreased while overnutrition has increased. ${ }^{5}$ The coexistence of different forms of malnutrition can be seen within the countries, and a double burden of undernutrition and overnutrition has become increasingly common in many parts of the world. ${ }^{6}$ Most countries have committed to achieve the World Health Assembly global nutrition targets by 2025 and the Sustainable Development Goals, ending malnutrition by $2030 .^{7}$ These commitments and goals present an unparalleled opportunity for action in countries.

Myanmar is a country with a high burden of malnutrition. ${ }^{3}$ A total of $50.4 \%$ of total deaths 
among children under 5 in the country in 2017 were attributable to potentiating effects of malnutrition. ${ }^{8}$ Myanmar is making significant efforts to address the nutrition situation. In May 2013, the country joined the global Scaling Up Nutrition (SUN) movement, a global movement led by countries to eliminate all forms of malnutrition in the world by 2030. ${ }^{9}$ Based on the guiding principles of the SUN movement that 'everyone has a right to food and good nutrition', the Government of Myanmar formulated the Myanmar National Action Plan for Food and Nutrition Security in 2015. ${ }^{9}$ Through it, the government and its partners planned to work together through collective multisectoral and multistakeholder action to accelerate the reduction in and eradication of food insecurity and undernutrition. ${ }^{9}$

However, important knowledge gaps regarding malnutrition in Myanmar remains, which hamper these efforts. While national prevalence of malnutrition has been presented, the prevalence and the potential variations on the subnational level (regions) is not known. Since Myanmar is a very diverse country both geographically and ethnically, simply exploring the malnutrition only at the national level might cause underestimation of the depth of the problem. The persistent malnutrition issues cannot be tackled effectively if the regional disparity is not thoroughly evaluated within the country. ${ }^{10}{ }^{11}$ In addition, studies assessing risk factors of malnutrition have used small samples from specific locations and are thus not generalisable to the national population.

The aim of the study was to provide data that can be used to design interventions for reducing malnutrition among children under 5 of Myanmar. We expect that the results of this study will help the policy makers and programme managers to be aware of to what extent malnutrition is affecting the children under 5 at the national level by which risk factors, and since we have used geographical mapping method for every region, it is easier to notice which regions require more attention than explanation with just data. The objectives of this study were: (1) to estimate the current national and regional prevalence of four types of malnutrition (stunting, wasting, underweight and overweight) among children under 5 in Myanmar; (2) to identify potential risk factors associated with each type of malnutrition and (3) to investigate how the identified risk factors' distributions explained the regional variations in malnutrition prevalence.

\section{Methods}

Data

In this study, we used secondary data from the 2015-2016 Myanmar Demographic and Health Survey (MDHS), a nationally representative, cross-sectional household survey conducted by Ministry of Health and Sport and its partners. MDHS included the household questionnaires and the women's questionnaires. The sampling design of MDHS was a stratified two-stage sampling in which 30 areas (15 urban areas and 15 rural areas) across 15 regions were used as strata. In the first stage, 442 clusters were selected from each stratum, with equal probability sampling and with independent selection. In the second stage, 30 households were selected from each cluster by equal probability systematic sampling. The response rate was $98 \%$ for the household questionnaires and $96 \%$ for the women's questionnaires. The survey collected information on maternal characteristics, child health, mortality data, family planning services and attitudes towards gender-based violence. For all children under 5 at the time of survey participation, anthropometric measurements (height and weight) were collected. The details of sampling methods and questionnaires were described in Myanmar DHS report. ${ }^{12}$

\section{Population and measurement}

\section{Target population}

A total of 4286 children under 5 were included in MDHS. After excluding those with incomplete anthropometric measurements $(\mathrm{n}=559)$, remaining 3727 children under 5 were included in the study population.

\section{Primary outcomes}

The primary outcomes of this study were (1) stunting (low height-for-age), (2) wasting (low weight-for-height), (3) underweight (low weight-for-age) and (4) overweight (high weight-for-height). Stunting is a sign of chronic malnutrition mainly due to inadequate nutrition during first 1000 days from pregnancy to the child's second birthday. ${ }^{13}$ Wasting is considered a more acute manifestation of malnutrition which is due to inadequate nutrition or illness leading to weight loss. ${ }^{12}$ Underweight is an indicator for both acute and chronic undernutrition. ${ }^{12}$ Overweight indicates a higher energy intake than expenditure. ${ }^{5}$

For the assessment of child nutritional status, the standardised Z-score developed by WHO was used. ${ }^{14}$ A child who has a Z-score of height-for-age, weight-for-height and weight-for-age below (-2 SD) of the median of the WHO reference population was considered short for his/her age (stunted), light for his/her height (wasted) and light for his/her age (underweight), respectively. ${ }^{14} \mathrm{~A}$ Z-score for weight-for-height above $(+2 \mathrm{SD})$ of the median of the WHO reference population was defined as overweight. ${ }^{14}$

\section{Covariates}

The covariates included in our analyses consisted of a three-level hierarchy: individual, household and community levels. The individual level variables were: child's age (categorised as $<6,6-11$ months, 12-23 months, 24-35 months, 36-47 months or 48-59 months), child's gender (male or female), mother's body mass index (underweight $<18.5 \mathrm{~kg} / \mathrm{m}^{2}$, normal $18.5-24.9 \mathrm{~kg} / \mathrm{m}^{2}$, overweight $25-30 \mathrm{~kg} / \mathrm{m}^{2}$ or obese $\left.30-50 \mathrm{~kg} / \mathrm{m}^{2}\right)$, mother's and father's education (no education, primary, secondary or more than secondary) and duration of preceding birth interval (zero (first births): 0 months, short: 9-24 months, medium: 25-48 months or long: 49 months and above). We also considered child's birth weight. In the 


\begin{tabular}{|c|c|c|}
\hline Variables & $\begin{array}{l}\text { Weighted } \\
\text { number of } \\
\text { children (n) }\end{array}$ & Percent (95\% Cls) \\
\hline \multicolumn{3}{|l|}{ Child's age (months) } \\
\hline$<6$ & 338 & 9.1 (8.2 to 10.0$)$ \\
\hline $6-11$ & 374 & 10.0 (9.1 to 11.0$)$ \\
\hline $12-23$ & 782 & 21.0 (19.7 to 22.3$)$ \\
\hline $24-35$ & 706 & 18.9 (17.7 to 20.2$)$ \\
\hline $36-47$ & 803 & 21.5 (20.3 to 22.9$)$ \\
\hline $48-59$ & 725 & 19.5 (18.2 to 20.8$)$ \\
\hline \multicolumn{3}{|l|}{ Child's gender } \\
\hline Male & 1921 & 51.5 (49.9 to 53.1$)$ \\
\hline Female & 1806 & 48.5 (46.9 to 50.1$)$ \\
\hline \multicolumn{3}{|l|}{$\begin{array}{l}\text { Preceding birth } \\
\text { interval* }^{*}\end{array}$} \\
\hline Zero (first births) & 1097 & 29.4 (28.0 to 30.9$)$ \\
\hline Short & 297 & 8.0 (7.1 to 8.9$)$ \\
\hline Medium & 845 & 22.7 (21.3 to 24.0$)$ \\
\hline Long & 1489 & 39.9 (38.4 to 41.5$)$ \\
\hline \multicolumn{3}{|c|}{ Breastfeeding practice } \\
\hline Exclusive & 1391 & 37.3 (35.8 to 38.9$)$ \\
\hline Non-exclusive & 2275 & 61.0 (59.5 to 62.6) \\
\hline Never & 62 & 1.7 (1.2 to 2.1$)$ \\
\hline
\end{tabular}

Mother's body mass

index

\begin{tabular}{|rrl|}
\hline Underweight & 446 & $12.0(11.0$ to 13.1$)$ \\
\hline Normal & 2353 & $63.3(61.7$ to 64.8$)$ \\
\hline Overweight & 718 & $19.3(18.1$ to 20.6$)$ \\
\hline $\begin{array}{l}\text { Obese } \\
\text { Mother's education }\end{array}$ & 201 & $5.4(4.7$ to 6.2$)$ \\
\hline No education & 618 & $16.6(15.4$ to 17.8$)$ \\
\hline Primary & 1758 & $47.2(45.6$ to 48.8$)$ \\
\hline Secondary & 1064 & $28.6(27.1$ to 30.0$)$ \\
\hline $\begin{array}{l}\text { Higher } \\
\text { Father's education }\end{array}$ & 288 & $7.7(6.9$ to 8.6$)$ \\
\hline $\begin{array}{l}\text { No education } \\
\text { Primary }\end{array}$ & 606 & $16.5(15.4$ to 17.8$)$ \\
\hline Secondary & 1532 & $41.8(40.2$ to 43.4$)$ \\
\hline Higher & 1316 & $35.9(34.4$ to 37.5$)$ \\
\hline Birth weight & 212 & $5.8(5.1$ to 6.6$)$ \\
\hline Low birth weight & 465 & $13.0(11.9$ to 14.1$)$ \\
\hline Normal & 3114 & $87.0(85.7$ to 88.1$)$ \\
\hline $\begin{array}{l}\text { Sociodemographic } \\
\text { status }\end{array}$ & & $22.7(21.3$ to 24.0$)$ \\
\hline $\begin{array}{l}\text { Poorest } \\
\text { Poorer }\end{array}$ & 1100 & \\
\hline & 844 & \\
\hline
\end{tabular}

Continued
Table 1 Continued

\begin{tabular}{|c|c|c|}
\hline Variables & $\begin{array}{l}\text { Weighted } \\
\text { number of } \\
\text { children (n) }\end{array}$ & Percent (95\% Cls) \\
\hline Middle & 643 & 17.3 (16.1 to 18.5$)$ \\
\hline Richer & 625 & 16.8 (15.6 to 18.0$)$ \\
\hline Richest & 516 & 13.8 (12.8 to 15.0$)$ \\
\hline \multicolumn{3}{|l|}{ Area of residence } \\
\hline Urban & 819 & 22.0 (20.7 to 23.3) \\
\hline Rural & 2908 & 78.0 (76.7 to 79.3$)$ \\
\hline \multicolumn{3}{|c|}{ Administrative regions } \\
\hline Kachin & 145 & 3.9 (3.3 to 4.5$)$ \\
\hline Kayah & 28 & 0.8 (0.5 to 1.1$)$ \\
\hline Kayin & 132 & 3.5 (3.0 to 4.2$)$ \\
\hline Chin & 56 & 1.5 (1.2 to 2.0$)$ \\
\hline Sagaing & 439 & 11.8 (10.8 to 12.9$)$ \\
\hline Taninthayi & 122 & 3.3 (2.7 to 3.9 ) \\
\hline Bago & 348 & 9.3 (8.4 to 10.3) \\
\hline Magway & 279 & 7.5 (6.9 to 8.4$)$ \\
\hline Mandalay & 391 & 10.5 (9.5 to 11.5$)$ \\
\hline Mon & 133 & 3.6 (3.0 to 4.2$)$ \\
\hline Rakhine & 266 & 7.2 (6.4 to 8.0$)$ \\
\hline Yangon & 402 & 10.8 (9.8 to 11.8$)$ \\
\hline Shan & 398 & 10.7 (9.7 to 11.7$)$ \\
\hline Ayeyarwaddy & 500 & $13.4(12.4$ to 14.5$)$ \\
\hline Naypyitaw & 88 & 2.4 (1.9 to 2.9$)$ \\
\hline
\end{tabular}

*Preceding birth interval: zero (first births): 0 month, short '9-24 months', medium '25-48 months', long ' 49 months and above'.

DHS survey, the question 'was the newborn very large, larger than average, average, smaller than average, or very small?' were asked to mothers. Birth weight is not usually recorded at birth in developing countries, and mothers' recall for child's birth size is commonly used as a proxy for birth weight. ${ }^{15}$ In a previous study conducted in Bangladesh, $90 \%$ of the mothers could correctly assess whether their newborn had low birth weight (LBW) or not. ${ }^{16}$ In this study, as with the previous study, we categorised the birth weights into LBW (mothers' recall of size of baby: very small or smaller than average) and non-LBW (average, larger than average, very large). ${ }^{1516}$

Household level variables included sociodemographic status, which was presented by wealth quintiles available in MDHS and in five categories: poorest, poorer, middle, richer and richest. Community level variables included areas of residence (urban and rural) and administrative regions.

\section{Statistical analysis}

Crude prevalence estimates

Prevalence of stunting, wasting, underweight and overweight in children under 5 was estimated at the national 


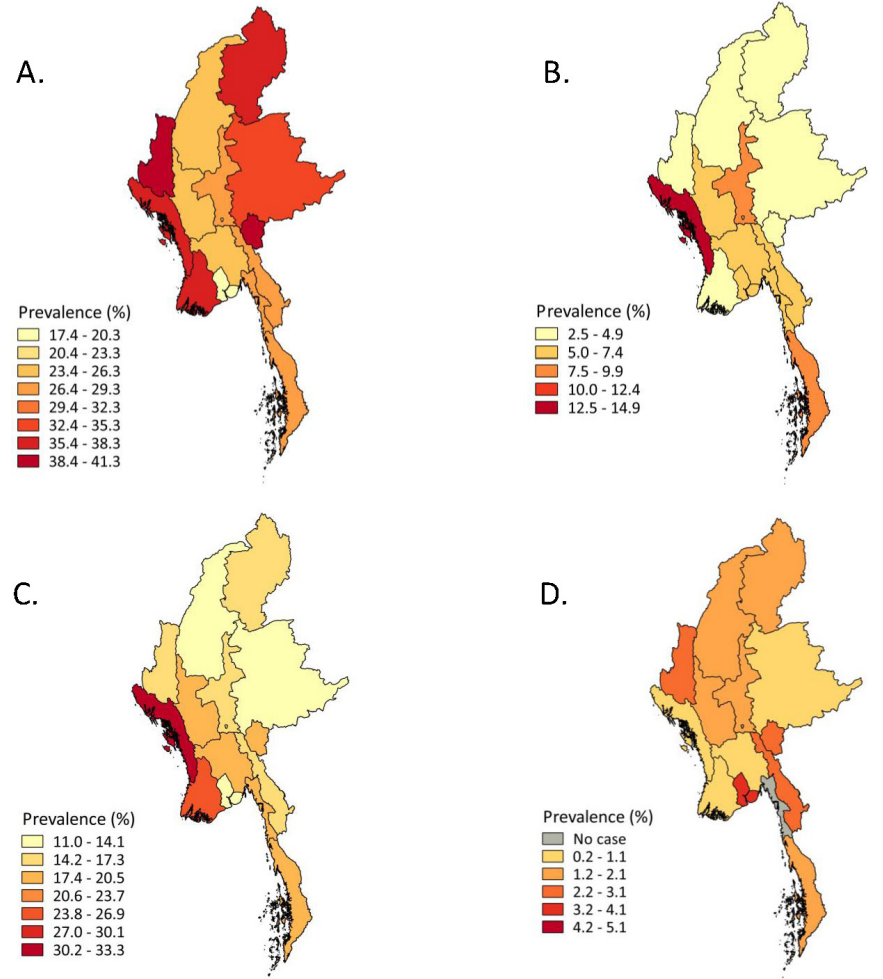

Figure 1 Crude prevalence of stunting (A), wasting (B), underweight (C) and overweight (D).

level and in each region separately. To control the effect of hierarchical sampling procedure in MDHS, unless indicated otherwise, numbers of samples and prevalence presented in this study were estimated, taking into account the sampling weights.

\section{Risks factor analyses}

Multivariable logistic regression analyses were conducted for risk factor identification for each of the four outcomes. Variable selection was performed using backward-stepwise method. Models were constructed separately for each malnutritional status: stunting, wasting, underweight and overweight.

\section{Adjusted prevalence estimates}

Based on the estimated parameters from the regression models, adjusted prevalence of the outcomes for each region was estimated in reference to the national average values for the risk factors. These regression-based, adjusted prevalence estimates were mapped to explore geographic variation in the country, showing regional variations not explained by the risk factors used in the study. All analyses were performed in Stata V.15/SE and the mapping was contructed in QGIS V.2.18. ${ }^{17} 18$

\section{Patient and public involvement}

Due to the study's retrospective nature using the secondary data from MDHS, no patients were involved in the study design or conduct of the study. There are no plans for dissemination of the outcomes of this research to the MDHS participants.
Table 2 Estimated prevalence of malnutrition among the study population

\begin{tabular}{|c|c|c|}
\hline Variables & $\begin{array}{l}\text { Weighted } \\
\text { number of } \\
\text { children (n) }\end{array}$ & Percent (95\% Cls) \\
\hline \multicolumn{3}{|l|}{ Stunting } \\
\hline Stunted & 1079 & 29.1 (27.7 to 30.6$)$ \\
\hline Not stunted & 2629 & 70.9 (69.4 to 72.3$)$ \\
\hline \multicolumn{3}{|l|}{ Wasting } \\
\hline Wasted & 250 & $6.8(6.0$ to 7.6$)$ \\
\hline Not wasted & 3448 & 93.2 (92.4 to 94.0) \\
\hline \multicolumn{3}{|l|}{ Underweight } \\
\hline Underweight & 679 & 18.3 (17.0 to 19.5$)$ \\
\hline Not underweight & 3042 & 81.8 (80.4 to 82.9$)$ \\
\hline \multicolumn{3}{|l|}{ Overweight } \\
\hline Overweight & 55 & 1.5 (1.1 to 1.9$)$ \\
\hline Not overweight & 3643 & 98.5 (98.1 to 98.9) \\
\hline
\end{tabular}

\section{RESULTS}

\section{Population characteristics}

Table 1 shows the demographic characteristics of the study population $(\mathrm{n}=3727)$. Mean age was 29 months (SD 17); $51.5 \%$ were male. The weighted number of LBW children was $465(13.0 \%)$. In total, $29.5 \%$ of the children were from the poorest families while $13.8 \%$ were from the richest families; and $78.0 \%$ were rural residents.

\section{Crude prevalence estimates at national and subnational level}

Taking into account the sampling strategy using sample weights and clustering, national prevalence of stunting, wasting, underweight and overweight in 2015-2016 in Myanmar was estimated to be $29.1 \%$ (95\% CIs $27.7 \%$ to $30.6 \%$ ), $6.8 \%$ (6.0\% to $7.6 \%$ ), $18.3 \%$ ( $17.0 \%$ to $19.5 \%$ ) and $1.5 \%$ (1.1\% to $1.9 \%$ ), respectively (table 2 ). Figure 1 presents the subnational prevalence of each type of malnutrition in the country, where numbers on an interval scale have equal intervals (as many as it can allow the variation in all regions). There were substantial regional variations in malnutrition, ranging from $19.1 \%(15.5 \%$ to $23.2 \%)$ to $41.1 \%$ (29.1\% to $54.3 \%$ ) for stunting, from $2.7 \%$ ( $0.6 \%$ to $12.7 \%$ ) to $12.9 \%$ (9.2\% to $17.3 \%$ ) for wasting, from $12.4 \%$ (9.6\% to $15.8 \%$ ) to $32.1 \%$ (26.7\% to $38.0 \%$ ) for underweight and from $0.0 \%(0.0 \%$ to $0.0 \%$ ) to $4.2 \%$ (2.6\% to $6.7 \%$ ) for overweight. High crude prevalence of stunting, wasting and underweight were observed in remote areas. For example, the highest crude prevalence of stunting was observed in Chin $(41.1 \%, 29.1 \%$ to $54.3 \%)$ followed by Kayah $(40.4 \%, 24.3 \%$ to $58.9 \%)$, while Rakhine had the highest prevalence of wasting $(12.9 \%, 9.2 \%$ to $17.3 \%)$ and underweight $(32.1 \%, 26.7 \%$ to $38.0 \%)$. In contrast, high prevalence of overweight was observed in high economic capital area, Yangon $(4.2 \%, 2.6 \%$ to $6.7 \%)$. Unlike other outcomes, there were no overweight case found in Mon and Nay Pyi Taw (capital) regions. Detailed prevalence 
(exact values) of malnutrition for each region can be found in online supplementary table 1 for stunting and wasting and in online supplementary table 2 for underweight and overweight.

\section{Risk factors of malnutrition}

Table 3 shows adjusted ORs (AORs) and 95\% CI for stunting, wasting, underweight and overweight. In multivariable analyses, adjusted for covariates, stunting and underweight were significantly and positively associated with LBW, with AORs of 2.06 (95\% CI 1.65 to 2.58, p<0.001) and 2.81 (2.24 to 3.53, $\mathrm{p}<0.001)$ in reference to non-LBW children. The statistically significant associations of wasting and overweight with LBW were not observed. In addition, children who had obese mothers had significantly lower odds of having stunted children $(0.53,0.35$ to $0.79, \mathrm{p}<0.05)$ than those having a mother in normal weight. Underweight mothers tended to have more wasted and underweight children compared with mothers with normal weight $(1.64,1.09$ to $2.48, \mathrm{p}<0.05$; and $1.34,1.03$ to $1.75, \mathrm{p}<0.05$, respectively).

After adjustment for covariates, the odds of stunting and underweight were the lowest in $<6$-month-old children (AORs $0.15,95 \%$ CI 0.09 to $0.23, \mathrm{p}<0.001$ and $0.27,0.17$ to $0.41, \mathrm{p}<0.001$ ), respectively, in reference to $48-59$-month-old children. Meanwhile, there were no significant differences observed in odds of overweight among different age groups. However, the odds of wasting in $<6$-month-old children were 1.99 (1.25 to $3.16, \mathrm{p}<0.01)$ times higher, in reference to 48-59-month-old children. Compared with children who were born after short preceding birth interval (9-24 months), first born children and children born after long preceding birth interval had lower odds of stunting $(0.62$, 0.46 to $0.85, \mathrm{p}<0.01$ and $0.62,0.47$ to $0.83, \mathrm{p}<0.01$ ), respectively. Compared with the children from middle wealth index group, those from richest group had 0.59 times lower odds of stunting ( 0.41 to $0.84, \mathrm{p}<0.01)$ after adjusted for covariates. Wasting was also significantly and negatively associated with wealth index in which children from richer group were lower odds $(0.58,0.34$ to $0.98, \mathrm{p}<0.05)$ compared with those from middle wealth index group.

\section{Adjusted subnational prevalence and unexplained regional variation}

Figure 2 presents the subnational adjusted prevalence of each type of malnutrition in reference to the national average values for the risk factors based on the estimated parameters from the regression models above. The cut-off points on scales for prevalence mapping were same with figure 1 (crude prevalence map) for better comparability between crude and adjusted prevalence of each outcome. Homogeneous prevalence of wasting was observed throughout the middle regions from north to south, and the highest prevalence was observed in Yangon $(11.0 \%$, 95\% CI $7.5 \%$ to $14.6 \%$ ) followed by Rakhine $(9.9 \%, 6.3 \%$ to $13.5 \%)$ and Tanintharyi $(9.2 \%, 3.9 \%$ to $14.6 \%)$. Similarly, the regional variation of stunting and overweight remained after the adjustment. Meanwhile, the adjusted prevalence of underweight showed narrowed variations and decreased prevalence in northern and eastern parts. Detailed adjusted prevalence of malnutrition for each region can be found in online supplementary table 1 for stunting and wasting and in online supplementary table 2 for underweight and overweight.

\section{DISCUSSION}

We estimated the prevalence of malnutrition among children under 5 at both the national and subnational levels in Myanmar, using nationally representative data and identified risk factors of malnutrition. This is the first study to include geographical mapping and discussed about regional variation in the prevalence of malnutrition. The prevalence of stunting, wasting, underweight and overweight were $29.1 \%$ ( $95 \%$ CI $27.7 \%$ to $30.6 \%$ ), $6.8 \%$ (6.0\% to $7.6 \%), 18.3 \%(17.0 \%$ to $19.5 \%)$ and $1.5 \%(1.1 \%$ to $1.9 \%)$, respectively.

In comparison with the reported prevalence of stunting and wasting in 1991 (53.6\% and 12.7\%), underweight in $1990(32.5 \%)$ and of overweight in 1997 (9.7\%) from the WHO's Global Observatory Data, ${ }^{19}$ there has been a substantial reduction in these conditions. ${ }^{19}$ Even though recent increase in prevalence was seen in other southeast Asian countries like Indonesia from $5.1 \%$ in 2004 to $11.5 \%$ in 2016 and Thailand from $7.3 \%$ in 2006 to $8.2 \%$ in 2016 , Myanmar did not show increasing prevalence of overweight among children. ${ }^{20}$ There were substantial variations in malnutrition prevalence across regions. Regions with more urban areas had lower prevalence of malnutrition (Yangon, Nay Pyi Taw). In some areas, the regional prevalence was much higher than the national prevalence. The regional variations persisted even after adjustment for risk factors including sociodemographic conditions.

Regional variations in nutritional status has mostly been seen in the countries where universal health coverage (UHC) has not yet been achieved. ${ }^{11}$ Myanmar is one of the countries that has not yet fully achieved UHC, and the healthcare services coverage is still approximately $50 \%-80 \% .{ }^{21}$ In terms of national nutrition actions coverage, only 3 out of 20 actions achieved $80 \%$ of targeted population coverage; salt iodisation, deworming, and health, nutrition and hygiene education in school. ${ }^{22}$ Low coverage was mostly seen in remote and civil conflict affected areas like Kachin, Chin and Rakhine. Another explanation for regional variations in nutritional status is that regional governments do not have full authority to handle the nutritional issues within their regions even though heath sector decentralisation was introduced in $1965 .{ }^{23}$ Most decisions are still made by the central government; this may complicate effective interventions tailored for each region. ${ }^{23}$

Several risk factors of malnutrition were identified in this study, including LBW and mother's nutrition. The main reason for LBW in most of the developing countries was found to be intrauterine growth retardation (IUGR) rather than prematurity. ${ }^{24}$ Most of the IUGR cases were associated with maternal factors, such as, nutrition and diet during pregnancy, young maternal age, low maternal height and 
Table 3 ORs and $95 \% \mathrm{Cl}$ of stunting, wasting, underweight and overweight

\begin{tabular}{|c|c|c|c|c|}
\hline Variables & Stunting & Wasting & Underweight & Overweight \\
\hline \multicolumn{5}{|l|}{ Child's age (months) } \\
\hline$<6$ & $0.15(0.09 \text { to } 0.23)^{\star \star \star}$ & $1.99(1.25 \text { to } 3.16)^{\star \star}$ & $0.27(0.17 \text { to } 0.41)^{\star \star *}$ & 2.52 (1.00 to 6.39$)$ \\
\hline $6-11$ & $0.31(0.22 \text { to } 0.45)^{* \star *}$ & 0.67 (0.37 to 1.22$)$ & $0.46(0.31 \text { to } 0.67)^{\star \star \star}$ & 1.84 (0.71 to 4.73 ) \\
\hline $12-23$ & $0.71(0.55 \text { to } 0.92)^{* *}$ & 1.12 (0.73 to 1.71$)$ & $0.58(0.44 \text { to } 0.76)^{\star \star *}$ & 1.27 (0.53 to 3.02$)$ \\
\hline 24-35 & $1.44(1.13 \text { to } 1.83)^{* *}$ & $0.72(0.45$ to 1.64$)$ & 0.89 (0.68 to 1.17$)$ & 0.29 (0.08 to 1.10$)$ \\
\hline $36-47$ & 1.20 (0.95 to 1.50$)$ & 0.68 (0.43 to 1.08$)$ & 0.88 (0.68 to 1.14$)$ & 0.65 (0.24 to 1.74$)$ \\
\hline $48-59$ & 1.00 & 1.00 & 1.00 & 1.00 \\
\hline \multicolumn{5}{|l|}{ Child's gender } \\
\hline Male & 1.00 & 1.00 & 1.00 & 1.00 \\
\hline Female & $0.79(0.67 \text { to } 0.93)^{* *}$ & 0.81 (0.61 to 1.08$)$ & 0.86 (0.72 to 1.02$)$ & $\begin{array}{l}0.40(0.21 \text { to } \\
0.74)^{\star \star}\end{array}$ \\
\hline \multicolumn{5}{|c|}{ Preceding birth interval ${ }^{*}$} \\
\hline Zero (first births) & $0.62(0.46 \text { to } 0.85)^{* *}$ & - & $0.71(0.50 \text { to } 0.99)^{\star}$ & - \\
\hline Short & 1.00 & - & 1.00 & - \\
\hline Medium & 0.88 (0.65 to 1.18$)$ & - & 0.77 (0.55 to 1.07$)$ & - \\
\hline Long & $0.62(0.47 \text { to } 0.83)^{* *}$ & - & $0.67(0.48 \text { to } 0.92)^{\star}$ & - \\
\hline \multicolumn{5}{|c|}{ Mother's body mass index } \\
\hline Underweight & 1.09 (0.87 to 1.38$)$ & $1.66(1.12 \text { to } 2.46)^{*}$ & $1.31(1.03 \text { to } 1.69)^{\star}$ & 1.00 (0.34 to 2.93$)$ \\
\hline Normal & 1.00 & 1.00 & 1.00 & 1.00 \\
\hline Overweight & 0.84 (0.68 to 1.04) & $0.96(0.63$ to 1.41$)$ & $0.65(0.49 \text { to } 0.84)^{\star *}$ & $1.97(1.02 \text { to } 3.79)^{*}$ \\
\hline Obese & $0.53(0.35$ to 0.79$)$ * & 1.32 (0.72 to 2.43$)$ & $0.36(0.20 \text { to } 0.63)^{\star \star \star}$ & $2.87(1.06 \text { to } 7.77)^{\star}$ \\
\hline \multicolumn{5}{|l|}{ Mother's education } \\
\hline No education & 1.00 & - & - & - \\
\hline Primary & 0.99 (0.78 to 1.26$)$ & - & - & - \\
\hline Secondary & 0.71 (0.53 to 0.95$)^{*}$ & - & - & - \\
\hline Higher & 1.02 (0.65 to 1.63$)$ & - & - & - \\
\hline \multicolumn{5}{|l|}{ Father's education } \\
\hline No education & 1.00 & 1.00 & 1.00 & - \\
\hline Primary & $0.76(0.60$ to 0.97$)$ * & $0.66(0.44 \text { to } 0.99)^{\star}$ & $0.62(0.48 \text { to } 0.79)^{\star \star \star}$ & - \\
\hline Secondary & $0.75(0.58 \text { to } 0.98)^{*}$ & 0.93 (0.61 to 1.44$)$ & $0.63(0.48 \text { to } 0.83)^{\star \star}$ & - \\
\hline Higher & 0.85 (0.52 to 1.40$)$ & 0.84 (0.41 to 1.71$)$ & $0.98(0.60$ to 1.61$)$ & - \\
\hline \multicolumn{5}{|l|}{ Birth weight } \\
\hline Normal & 1.00 & 1.00 & 1.00 & 1.00 \\
\hline Low birth weight & 2.06 (1.65 to 2.58$)^{* \star *}$ & 1.36 (0.92 to 2.00$)$ & $2.81(2.24 \text { to } 3.53)^{\star \star \star}$ & 1.73 (0.81 to 3.73 ) \\
\hline \multicolumn{5}{|c|}{ Sociodemographic status } \\
\hline Poorest & 1.18 (0.92 to 1.52$)$ & 1.11 (0.72 to 1.73$)$ & 1.11 (0.83 to 1.48$)$ & 0.82 (0.26 to 2.59$)$ \\
\hline Poorer & 1.23 (0.95 to 1.58$)$ & 0.79 (0.50 to 1.26$)$ & 1.11 (0.82 to 1.48$)$ & 2.19 (0.84 to 5.68$)$ \\
\hline Middle & 1.00 & 1.00 & 1.00 & 1.00 \\
\hline Richer & 0.96 (0.72 to 1.27$)$ & $0.58(0.34 \text { to } 0.98)^{\star}$ & 0.99 (0.71 to 1.37$)$ & 1.65 (0.61 to 4.50$)$ \\
\hline Richest & $0.59(0.41 \text { to } 0.84)^{* *}$ & 0.99 (0.59 to 1.63$)$ & 0.81 (0.55 to 1.19) & 1.67 (0.60 to 4.65$)$ \\
\hline \multicolumn{5}{|c|}{ Administrative regions } \\
\hline Kachin & 1.57 (0.97 to 2.52) & $0.23(0.08 \text { to } 0.67)^{\star *}$ & 0.89 (0.50 to 1.56$)$ & 0.55 (0.14 to 2.19$)$ \\
\hline Kayah & 2.17 (0.91 to 5.15$)$ & 0.24 (0.03 to 2.19$)$ & 1.04 (0.37 to 2.95$)$ & 0.94 (0.09 to 9.15) \\
\hline Kayin & 0.93 (0.55 to 1.56$)$ & $0.38(0.16 \text { to } 0.88)^{*}$ & 0.65 (0.36 to 1.19$)$ & $0.76(0.22$ to 2.58$)$ \\
\hline Chin & $1.92(1.1 .01 \text { to } 3.65)^{*}$ & 0.20 (0.04 to 1.01$)$ & 0.81 (0.36 to 1.81$)$ & 0.81 (0.14 to 4.65$)$ \\
\hline
\end{tabular}




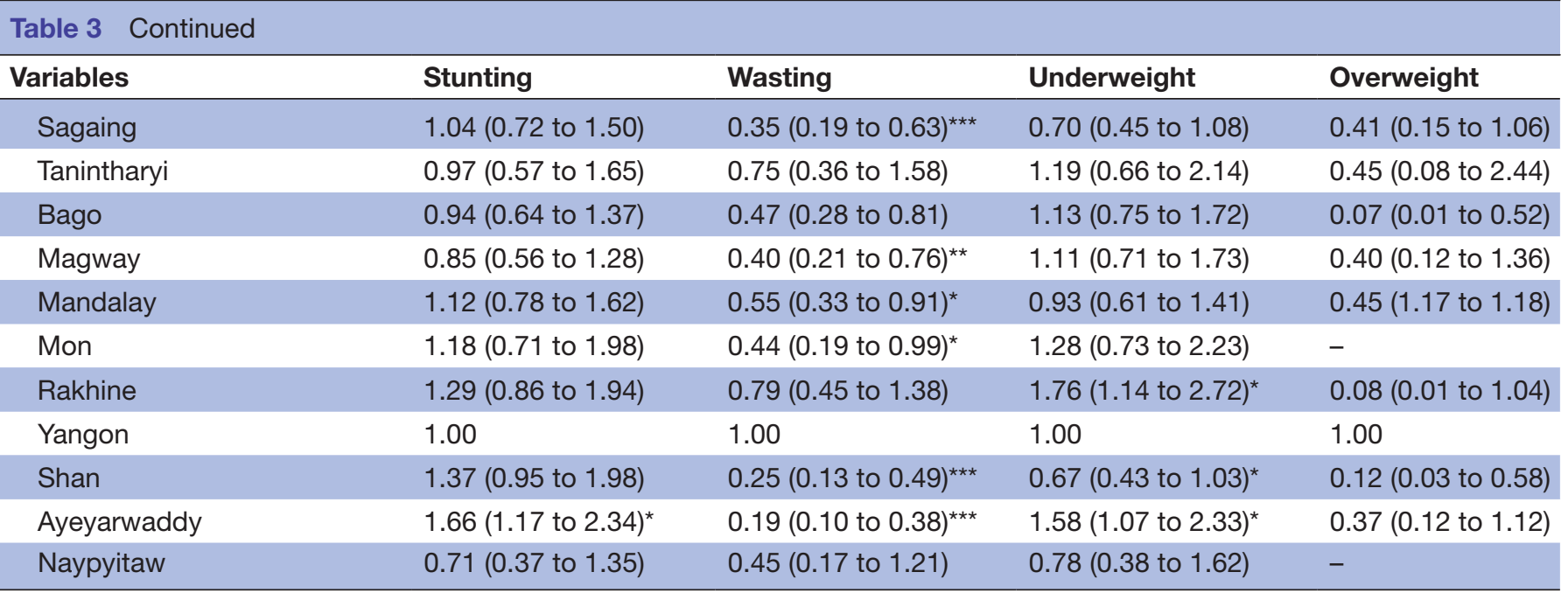

*Preceding birth interval: zero (first births): 0 month, short '9-24 months', medium '25-48 months', long '49 months and above'; * $\mathrm{p}<0.05$,

${ }^{* *} \mathrm{p}<0.01,{ }^{* \star *} \mathrm{p}<0.001$.

weight and presence of diseases (eg, hypertension). ${ }^{25}$ IUGR-LBW affects the child throughout his/her life and associates with higher incidence of type two diabetes, hypertension and cardiovascular disease. ${ }^{26}$ The study showed that LBW was a significant risk factor for childhood undernutrition even after being adjusted for well-known risk factors, such as, mothers' and fathers' education and different
A.

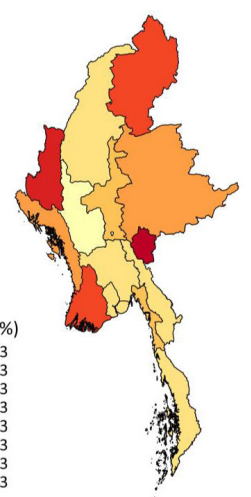

C.

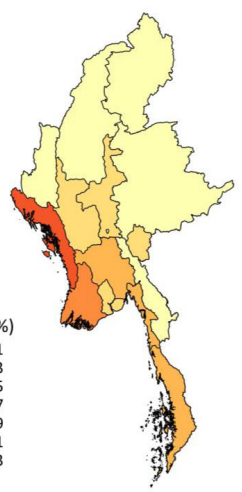

B.

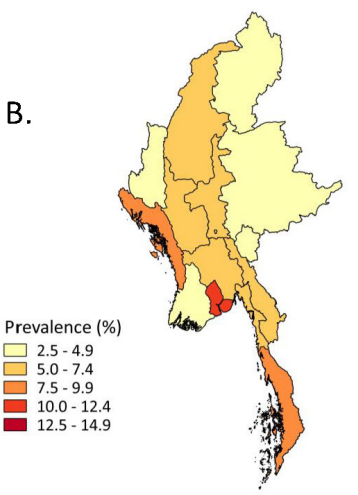

D.

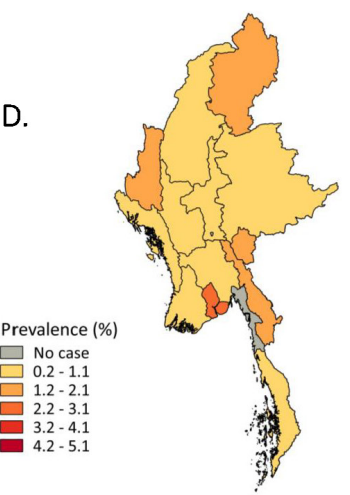

Figure 2 Adjusted prevalence of stunting (A), wasting (B), underweight (C) and overweight (D). Birth weight, chid's age and gender, parental education, mother's body mass index, preceding birth interval and sociodemographic status were adjusted. socioeconomic status. Therefore, LBW should be considered as one of important risk factors for stunting and underweight among children under 5 .

As observed in previous studies from other countries, children from poorest families were at higher risk of malnutrition, in particular stunting. ${ }^{16}{ }^{27}$ In this study, children from richest group were nearly half time lower odds of being stunted compared with those from middle groups (reference). It is widely known that poverty and malnutrition reinforce each other and efforts to address malnutrition in the poorest groups are much needed. ${ }^{4}$ One of the thing that we can exclude depending on the result of this study is that we did not find any double burden of malnutrition, such as maternal overweight and child underweight/ stunting.

\section{Limitations of this study}

Our study has limitations. First, the observational nature of the study did not allow for assessing causal relationships between risk factors and malnutrition. Second, birth weight was categorised based on the mother's recall of the birth size of the child; this might have introduced recall bias as well as uncertainty regarding the specificity and generalisability of this exposure. This is a well-known limitation of the DHS surveys. Third, even though we have assessed the possibility of unexplained risk factors' presence, we could not identify which factors are responsible.

\section{CONCLUSION}

This study has provided prevalence estimates of stunting, wasting, underweight and overweight among children under 5 at the national as well as the subnational level in Myanmar. Prevalence of the different types of malnutrition varied markedly across regions of the country. This variation persisted even after adjustment for the identified risk factors of each type of malnutrition. Several risk factors of malnutrition were identified, including LBW and 
inadequate maternal nutritional status. There is plenty of scope for reducing the burden of malnutrition among children under 5 in Myanmar by addressing these risk factors. Future interventions aimed at improving the nutritional status of children under 5 in Myanmar should consider the regional variations in prevalence. Further research is needed to investigate the potential sources of regional variation in prevalence of malnutrition in children under 5 in the country.

Acknowledgements We thank Dr Md Mizanur Rahman and Mr Md Shafiur Rahman for giving us utmost assistance and valuable suggestions.

Contributors All authors conceived and designed the study and take responsibility for the accuracy of the data analysis. HTK, SN, DY, PU and KS analysed and interpreted the data. HTK conducted statistical analysis and drafted the article. All authors made critical revision of the manuscript for important intellectual content and gave final approval for the manuscript.

Funding The authors have not declared a specific grant for this research from any funding agency in the public, commercial or not-for-profit sectors.

Map disclaimer The depiction of boundaries on the map(s) in this article do not imply the expression of any opinion whatsoever on the part of BMJ (or any member of its group) concerning the legal status of any country, territory, jurisdiction or area or of its authorities. The map(s) are provided without any warranty of any kind, either express or implied.

Competing interests None declared.

Patient consent for publication Not required.

Ethics approval Ethical approval for this study was not required as the data were extracted from the MDHS which did not contain any personally identifiable information.

Provenance and peer review Not commissioned; externally peer reviewed.

Data availability statement Data are available upon reasonable request. No data are available.

Open access This is an open access article distributed in accordance with the Creative Commons Attribution Non Commercial (CC BY-NC 4.0) license, which permits others to distribute, remix, adapt, build upon this work non-commercially, and license their derivative works on different terms, provided the original work is properly cited, appropriate credit is given, any changes made indicated, and the use is non-commercial. See: http://creativecommons.org/licenses/by-nc/4.0/.

\section{REFERENCES}

1. World Health Organization. What is malnutrition? 2016. Available: http://www.who.int/features/qa/malnutrition/en/ [Accessed 7Jan 2019].

2. $\mathrm{Kyu} \mathrm{HH}$, Abate $\mathrm{D}$, Abate $\mathrm{KH}$, et al. Global, regional, and national disability-adjusted life-years (DALYs) for 359 diseases and injuries and healthy life expectancy (HALE) for 195 countries and territories, 1990-2017: a systematic analysis for the global burden of disease study 2017. The Lancet 2018;392:1859-922.

3. United nations children's funds. UNICEF data, 2019. Available: https://data.unicef.org/topic/nutrition/malnutrition/ [Accessed 7Jan 2019].

4. Smith LC, Haddad L. Reducing child undernutrition: past drivers and priorities for the Post-MDG era. World Dev 2015;68:180-204.
5. Abarca-Gómez L, Abdeen ZA, Hamid ZA, et al. Worldwide trends in body-mass index, underweight, overweight, and obesity from 1975 to 2016: a pooled analysis of 2416 population-based measurement studies in 128.9 million children, adolescents, and adults. The Lancet 2017;390:2627-42.

6. World Health Organization. Double burden of malnutrition, 2019. Available: https://www.who.int/nutrition/double-burden-malnutrition/ en/ [Accessed 14 Feb 2019].

7. World Health Organization. Nutrition: global targets 2025, 2014 Available: https://www.who.int/nutrition/global-target-2025/en/ [Accessed January 7, 2019].

8. Roth GA, Abate D, Abate $\mathrm{KH}$, et al. Global, regional, and national age-sex-specific mortality for 282 causes of death in 195 countries and territories, 1980-2017: a systematic analysis for the global burden of disease study 2017. The Lancet 2018;392:1736-88.

9. ScalingUp Nutrition (SUN). ScalingUp nutrition engage, Inspire, invest, 2015. Available: http://scalingupnutrition.org/sun-countries/ myanmar/ [Accessed 7 Jan 2019].

10. Braveman P. What are health disparities and health equity? we need to be clear. Public Health Rep 2014;129(1 suppl2):5-8.

11. Devaux M. Income-Related inequalities and inequities in health care services utilisation in 18 selected OECD countries. The European Journal of Health Economics 2015;16:21-33.

12. Ministry of Health and Sports. Myanmar demographic and health survey (2015-16. Rockville: Ministry of Health and Sports and ICF, 2016.

13. de Onis M, Dewey KG, Borghi E, et al. The world Health organization's global target for reducing childhood stunting by 2025 : rationale and proposed actions. Matern Child Nutr 2013;9(Suppl. 2):6-26.

14. World Health Organization. Who child growth standards: length/ height for age, weight-for-age, weight-for-length, weight-for-height and body mass index-for-age, methods and development. World Health Organization, 2006.

15. Channon AAR. Can mothers judge the size of their newborn? assessing the determinants of a mother's perception of a baby's size at birth. J Biosoc Sci 2011;43:555-73.

16. Rahman MS, Howlader T, Masud MS, et al. Association of Low-Birth weight with malnutrition in children under five years in Bangladesh: do mother's education, socio-economic status, and birth interval matter? PLoS One 2016;11:e0157814.

17. QGIS. A free and open source geographic information system, 2019. Available: https://qgis.org/en/site/ [Accessed 20 Jun 2019].

18. STATA. STATA software, 2019. Available: https://www.stata.com/ [Accessed 20 Jun 2019].

19. World Health Organization. Global health observatory (GHO) data, 2015. Available: http://apps.who.int/gho/tableau-public/tpc-frame. jsp?id=402 [Accessed 7 Jan 2019].

20. World Health Organization. World health statistics 2018: monitoring health for the SDGs, sustainable development goals, 2018.

21. Han SM, Rahman MM, Rahman MS, et al. Progress towards universal health coverage in Myanmar: a national and subnational assessment. The Lancet Global Health 2018;6:e989-97.

22. ScalingUp Nutrition (SUN). Outcome 1: increased awareness of the causes of malnutrition and potential solutions, 2017. Available: https://www.unnetworkforsun.org/outcome-1 [Accessed 7 Jan 2019].

23. Sein TT, Myint P, Tin N. The Republic of the Union of Myanmar health system review. . European Observatory on Health Systems and Policies, 2014: 4. 5-3.

24. Villar J, Belizán J. The relative contribution of prematurity and fetal growth retardation to low birth weight in developing and developed societies. Am J Obstet Gynecol 1982;143:793-8.

25. Suhag A, Berghella V. Intrauterine growth restriction (IUGR): etiology and diagnosis. Curr Obstet Gynecol Rep 2013;2:102-11.

26. UNICEF and World Health Organization. Low birthweight: country, regional and global estimates. New York: Unicef, 2004

27. Rachmi CN, Agho KE, Li M, et al. Stunting, underweight and overweight in children aged 2.0-4.9 years in Indonesia: prevalence trends and associated risk factors. PLoS One 2016;11:e0154756. 